\title{
Nebulisers for bronchiectasis
}

\author{
D C Currie
}

Almost all patients with bronchiectasis expectorate sputum intermittently or daily. The sputum ranges from mucoid to purulent and from scanty to copious. Patients with bronchiectasis have a number of other symptoms some are breathless with impaired lung function, usually predominantly an obstructive ventilatory defect, and asthma is frequent with an incidence of $28 \%$ (10 of 36) and 39\% (nine of 23) having been reported in studies from Ireland $^{1}$ and England. ${ }^{2}$ Bronchial hyperreactivity to histamine ${ }^{3}$ and methacholine ${ }^{4}$ reported in $48 \%$ and $69 \%$ of patients is of uncertain significance in the presence of bronch damaged by the primary disease process. In addition to local symptoms, patients with daily purulent sputum expectoration have systemic symptoms such as malaise and tiredness both during and between acute exacerbations. ${ }^{2}$

Patients with bronchiectasis are at risk of disease progression. Forced expiratory volume in one second $\left(\mathrm{FEV}_{1}\right)$ declined by $>50 \mathrm{ml}$ year in $80 \%$ of a group of 71 patients $^{5}$ and radiographs had deteriorated in $18 \%$ of a group of 84 patients by the time of tertiary referral. Daily purulent sputum expectoration, indicative of a significant host inflammatory response, ${ }^{7}$ is likely to be an important risk factor for progression, although this is unproven.

\section{Indications for nebulisers in}

bronchiectasis

Few studies have been published on the use of nebulisers in bronchiectasis. The possible indications for nebulisers are (1) reversal of airways obstruction with bronchodilators in patients with and without asthma, (2) improvement of mucus clearance, and (3) reduction of the microbial load in the bronchial tree.

BRONCHODILATOR REVERSAL OF AIRWAYS OBSTRUCTION

No studies have been identified that were designed to evaluate the use of bronchodilator drugs for reversal of airways obstruction in patients with bronchiectasis. At present it is therefore appropriate to follow guidelines for patients with asthma ${ }^{8}$ and chronic obstructive pulmonary disease ${ }^{9}$ without bronchiectasis (see also paper by O'Driscoll on pp S49-52). Those patients prescribed nebulised antibiotics may

Dewsbury and District Hospital, Healds Road, Dewsbury, Wes

UK require nebulised bronchodilators beforehand (see paper by Webb and Dodd on pp S69-71).

IMPROVEMENT OF MUCUS CLEARANCE

Correspondence to:
Dr D C Currie. modern chest physiotherapy were evaluated in a randomised study ${ }^{10}$ of eight patients with stable bronchiectasis. Both nebulised treatments significantly increased the yield of expectorated fluid/mucus by a small amount, similar to the weight of the nebulised solution (only a $25 \%$ increase in the expectorated weight compared with physiotherapy alon ingly, creased the radioaerosol clearance rate in patients with stable bronchiectasis. ${ }^{8}$ Nebulised water ${ }^{11}$ combined with physiotherapy resulted in an increase in the amount of sputum expectorated and the total lung radiolabel clearance rate that was similar to physiotherapy alone in a group of seven patients with bronchiectasis and no evidence of asthma.

Hypertonic saline $(7.1 \%)$ significantly increased the weight of sputum produced and the whole lung radioaerosol clearance rate in 11 patients with chronic bronchitis. ${ }^{12}$ In the same study the mucolytic agent, 2-mercaptoethane sulphonate, had similar effects to hypernicat sigThere are no published studies on sthe ${ }^{2}$ There are no published studies on the use of $\mathrm{N}$-acetylcysteine in patients with bronchiectasis without cystic fibrosis. Sixty patients with stable purulent bronchiectasis treated for two weeks with nebulised rhDNase showed no improvement in $\mathrm{FEV}_{1}$ or sputum production in a double blind placebo controlled study. ${ }^{13}$

The clinical importance of these observations on mucus clearance is unknown.

REDUCTION OF COLONISING MICROBIAL LOAD IN THE BRONCHIAL TREE

The objective of nebulised antimicrobial therapy in patients with bronchiectasis is to reduce the colonising microbial load in the lungs, improve symptoms, and prevent progression of the disease. Nebulised antimicrobial agents are usually prescribed for control of background symptoms and for the reduction of severity or prevention of acute exacerbations rather than for treatment of acute exacerbations.

\section{Methodology}

Evaluation of the effectiveness of nebulised antimicrob chiectasis should include assessment of sputum character and volume. ${ }^{14}$ The 24 hour volume of sputum should be estimated from the history or, preferably, measured. A fresh four hour morning sample of sputum should be examined to establish the proportion of purulent sputum and the degree of purulence (colour (green/yellow) and intensity of colour). This allows estimation of the 24 hour volume of purulent sputum. The 
volume of purulent sputum was a better discriminator than sputum elastase levels for separating the antibiotic treated group from the placebo group in a study of long term higher dose amoxycillin (3 $\mathrm{g}$ twice daily for seven months). ${ }^{2}$ The erythrocyte sedimentation rate and white blood count are inconsistently raised in patients with purulent bronchiectasis between exacerbations ${ }^{2}$ with no obvious correlation to purulent sputum volume. Serial quantitative sputum bacterial culture ${ }^{14}$ is a possible way of monitoring the response to nebulised antibiotics. However, no recognised pathogens were isolated in eight of 36 patients with purulent bronchiectasis despite extensive and repeated culture on selective and nonselective media. ${ }^{2}$ Lung function seems less likely to be reduced by the presence of purulen sputum or its production in patients with bronchiectasis without cystic fibrosis than in patients with cystic fibrosis. Prolonged higher dose oral amoxycillin ( $3 \mathrm{~g}$ twice daily) reduced the volume of purulent sputum in a double blind placebo controlled study but did not alter lung function. ${ }^{2}$ Data on nebulised antibiotics in patients with cystic fibrosis may not be applicable to other patients with bronchiectasis. In addition, quality of life between exacerbations and severity of exacerbation should be evaluated.

\section{STUDIES}

Sputum volume and purulence decreased and peak expiratory flow rate (PEFR) improved during prolonged treatment with nebulised amoxycillin $500 \mathrm{mg}$ (intravenous preparation diluted in $5 \mathrm{ml}$ sterile water, unlicensed indication) twice daily in an open study ${ }^{15}$ of six patients whose daily purulent sputum expectoration had failed to improve with ora higher dose amoxycillin ( $3 \mathrm{~g}$ twice daily). These improvements occurred despite culture of apparently resistant organisms.

Prolonged nebulised antifungal therapy with natamycin was unhelpful in a double blind placebo controlled study ${ }^{16}$ of patients with allergic bronchopulmonary aspergillosis, many of whom had evidence of bronchiectasis (D C Currie, personal communication).

\section{TECHNIQUE AND DRUGS}

The main potential problems with nebulised antimicrobial therapy are bronchospasm and/ or chest tightness. These are especially relevant in a disease characterised by increased bronchial hyperreactivity and asthma. The characteristics of the final drug solution, in particular isotonicity, and the nebuliser system are important. The clinical relevance and frequency of the selection of antibiotic resistant organisms are unknown. The frequent use of antibiotics orally and intravenously in patients with purulent sputum complicates the assessment of the balance between risk and benefit of the nebulised route for antibiotics.

Nebulised colistin ${ }^{17}$ aminoglycosides, antipseudomonal penicillins, and third generation cephalosporins have been prescribed for individual patients in recent years. Controlled studies of efficacy are long overdue.

\section{Recommendations for the use of}

nebulised antibiotics in bronchiectasis

Long term nebulised antibiotics should be considered when background symptoms, severity of acute exacerbations, or risk of progression warrant them, provided that antibiotics by other routes combined with regular postura drainage have been found unsuccessful, undrainge have been fou biotics should usually be used as an adjunct to regular home postural drainage and courses of oral or intravenous antibiotics for acute exacerbations.

\section{CHOICE OF ANTIBIOTIC}

Sputum culture may not reveal the particular bacteria responsible for triggering the host inflammatory response. The presence of Pseudomonas aeruginosa makes response to nonantipseudomonal antibiotics less likely ${ }^{2}$ and should encourage use of nebulised antipseudomonal antibiotics analogous to their usage in patients with cystic fibrosis with similar drugs and dosag paper on pp S69-71). Nebulised gentamicin $(80 \mathrm{mg}$ twice daily, each dose diluted with $0.9 \%$ saline to a total volume of $4 \mathrm{ml}$, unlicensed indication) is presently the author's preferred choice. In addition, nebulised amoxycillin $(500 \mathrm{mg}$ twice daily diluted in 3-5 ml sterile water; unlicensed indication) is worth considering in patients intolerant of oral amoxycillin as a result of gastrointestinal ter gastrointestinal side effects or vaginal candidiasis.

\section{ANTIBIOTIC DELIVERY}

Antibiotics require either a breath controlled open vent nebuliser such as the Ventstream (Medic-Aid Ltd) with a standard compressor or a high powered compressor with a standard nebuliser (see paper by Webb and Dodd on pp S69-71). A single dose trial of nebulised antibiotic is advisable with measurement of PEFR and spirometric parameters before, immediately after, and 15 minutes after nebulisation. ${ }^{18}$

It is logical for nebulised antibiotics to be preceded by self-physiotherapy and, if necessary, bronchodilators. Precise recommendations with respect to use of outflow filters or venting out of the window are not possible. Further research is required in this area. The approach outlined in the paper on cystic fibrosis is one possible strategy. However, it may be polp helpful to use them at home as well as in

\section{EVALUATION}

Treatment must be carefully evaluated in each patient. Specific questions should be answered. acerbations reduced after starting nebulised 
antibiotics? Does the patient feel better? Are the sputum-related acute exacerbations reduced in frequency and/or severity? Is lung function improved?

If the drug is ineffective or not taken regularly, it should be stopped. A guide time for the evaluation of benefit from nebulised antibiotics is three months.

\section{Conclusion}

A therapeutic trial of long term nebulised antibiotics with careful evaluation is justified in individual patients when background symptoms, severity of acute exacerbations, or risk of progression warrant antibiotic therapy, provided that antibiotics by other routes combined with regular postural drainage have been unwith regular postural drainage have been unbe used as an adjunct to home postural drainage and courses of oral or intravenous antibiotics for acute exacerbations.

Nebulised bronchodilator therapy is indicated in a small number of patients with bronchiectasis and the need should be evaluated as for patients with asthma and chronic ated as for patients with asth
obstructive airways disease.

1 Murphy MB, Reen DJ, Fitzgerald MX. Atopy, immunoThorax 1984;39:179-84. 2 Currie DC, Garbett ND, Chan KL, Higgs E, Todd H,
Chadwick MV, et al. Double blind randomised placeboChadwick MV, et al. Double blind randomised placebo-
controlled study of prolonged high dose oral amoxycillin in purulent bronchiectasis. $Q$ F Med 1990;76:799-816.
Varpela E, Laitinen LA, Keskinen H, Korhola O. Asthma, Varpela E, Laitinen LA, Keskinen H, Korhola O. Asthma,
allergy and bronchial hyperreactivity to histamine in
patients with bronchiectasis. Clin Allergy 1 1978;8:273-80.
4 Bahous J, Cartier A, Pineau L, Bernard C, Ghezzo H, Martin RR, et al. Pulmonary function tests and airway responsiveness to metacholine in chronic bronchiectasis
of the adult. Bull Eur Physiopathol Respir 1984;20:375-80. Ellis DA, Thornley PE, Wightman AJ, Walker M, Chalmers and social study and review of factors influencing proghosis. Thorax 1981;36:659-64. Radiological evidence of progression of bronchiectasis.

7 Respir Med 1992;86:397-401. bronchiectasis. Eur f Respir Dis 1986;69 (Suppl 147): British Thoracic Society, National Asthma Campaign, Royal lines on asthma management: 1995 review and positiostatement. Thorax 1997:52(Suppl 1):S1-21. British Thoracic Society. Guidelines on the management of press) obstructive pulmonary disease. Thorax 1997 (in 10 Sutton PP, Gemmell HG, Innes N, Davidson J, Smith FW,
Legge JS, et al. Use of nebulised saline and nebulised
terbutaline as an adjunct to chest physiotherapy. Thorax 1988:43:57-60.
Conway JH, Fleming JS, Perring S, Holgate ST. HuConway JH, Fleming JS, Perring S, Holgate ST. Hu-
midification as an adjunct to chest physiotherapy in aiding Pavia D, Sutton PP, Lopez-Vidriero MT, Newman SP Clarke SW. Drug effects on mucociliary function. Eur 13 Wills PJ, Wodehouse T, Corkery K, Fick R, Cole PJ. A short-term placebo-controlled trial of recombinant human
DNAse in idiopathic bronchiectasis. Crit Care Med 1994; 149:A181 (abstract).
Currie DC, Higgs E, Metcalfe S, Roberts DE, Cole PJ. Simple method of measuring colonising microbial load in

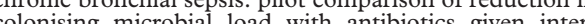
mittently and continuously. F Clin Pathol 1987;40:830-6. 15 Stockley RA, Hill SL, Burnett D. Nebulized amoxycillin in chronic purulent bronchiectasis. Clin Ther 1985;7:593-9.
Currie DC, Lueck C, Milburn H, Harvey C, Longbottom
JL, Darbyshire JH, et al. Double blind placebo-controlled trial of nebulised natamycin in patients with allergic bronchopulmonary aspergillosis. Thorax 1990;45:447-50.
17 Rose HD, Pendharker MB, Snider GL, Kory RC. Evaluation of sodium colistomethate aerosol in Gram-negative in-
fections of the respiratory tract. $\mathcal{F}$ Clin Pharmacol 1970; 10:274-81. Maddison J, Dodd M, Webb AK. Nebulised colistin causes
chest tightness in adults with cystic fibrosis. Respir Med 